\title{
Chalk-stick fracture in ankylosing spondylitis
}

\section{Konstantinos Skarentzos ${ }^{1} \cdot$ Georgia Karamanou ${ }^{1} \cdot$ Ioannis $_{\text {Chrysafis }}{ }^{2} \cdot$ Charalampos Papagoras $^{3}$}

Received: 17 March 2020 / Revised: 9 April 2020 / Accepted: 16 April 2020 / Published online: 6 May 2020

(C) International League of Associations for Rheumatology (ILAR) 2020

\section{Presentation}

A 49-year-old man came to the emergency department, because of back pain after a fall from his own height. Due to a history of ankylosing spondylitis (AS), his back had already been painful and stiff, though the pain had abruptly worsened since the fall. On examination, he had normal vital signs and no evident internal organ or nervous system injury. However, his kyphotic spine was moderately tender, particularly at the thoracolumbar area. Plain radiographs (Fig. 1a, b) revealed complete sacroiliac and spinal ankylosis except for the T9T10 space, which, instead, seemed slightly widened (arrow). To rule out a spinal injury, a computed tomography (CT) was performed. The 3D reconstruction of the $\mathrm{CT}$ (Fig. 1c) revealed a spinal fracture through the T9-T10 intervertebral disc (arrow) up to the posterior vertebral elements completely dissecting the spine (chalk-stick fracture). The patient was prescribed braces and advised to remain at bed rest. In the following weeks, his back pain gradually improved and he resumed his prior activity.

\section{Discussion}

In AS patients, spinal fractures occur up to fourfold more frequently than the general population, with a lifelong incidence of $5-15 \%$ [1]. They often result from a low-energy trauma to the rigid and osteopenic spine and affect predominantly the cervical $(81.2 \%)$ rather than the thoracic $(10.7 \%)$ or

Charalampos Papagoras

cpapagor@med.duth.gr

1 Department of Medicine, Democritus University of Thrace, Alexandroupolis, Greece

2 Department of Radiology, University Hospital of Alexandroupolis, Alexandroupolis, Greece

3 First Department of Internal Medicine, University Hospital of Alexandroupolis, Democritus University of Thrace, Dragana, 68100 Alexandroupolis, Greece lumbar spine (7.8\%). Neurologic deficits are evident in up to $67.2 \%$ of patients upon admission $[2,3]$. The treatment may be surgical or conservative depending on the stability of the fracture, presence of neurologic complications and the patient's general condition [1].

Regarding diagnosis, plain radiographs and even transverse CT images may fail to show the disruption of bone contours. Therefore, when facing patients with spinal ankylosis, a high degree of suspicion is warranted, so as to rule out this potentially devastating injury by appropriate imaging.

\section{Compliance with ethical standards}

Disclosures None.

Financial support received for the study None.

Ethical approval Approval has been received by the Institutional Review Board of University Hospital of Alexandroupolis, ES6/T13/289-2017, and all procedures are in accordance with the 1964 Declaration of Helsinki.

Informed consent The patient's written informed consent to publish the material has been obtained.

\section{References}

1. Chaudhary SB, Hullinger H, Vives MJ (2011) Management of acute spinal fractures in ankylosing spondylitis. ISRN Rheumatol 2011: 150484-150489. https://doi.org/10.5402/2011/150484

2. Westerveld LA, Verlaan JJ, Oner FC (2009) Spinal fractures in patients with ankylosing spinal disorders: a systematic review of the literature on treatment, neurological status and complications. Eur Spine J 18:145-156. https://doi.org/10.1007/s00586-008-0764-0

3. Caron T, Bransford R, Nguyen Q, Agel J, Chapman J, Bellabarba C (2010) Spine fractures in patients with ankylosing spinal disorders. Spine (Phila Pa 1976) 35:E458-E464. https://doi.org/10.1097/BRS. 0b013e3181cc764f

Publisher's note Springer Nature remains neutral with regard to jurisdictional claims in published maps and institutional affiliations. 
Fig. 1 a Anteroposterior pelvis radiograph showing complete

obliteration and residual sclerosis of both sacroiliac joints,

consistent with ankylosing

spondylitis. b Lateral radiograph

of the thoracolumbar spine

showing total spinal ankylosis

except for the T9-T10 space,

which appears wider than the ad-

jacent spaces (arrow). c Three-

dimensional reconstruction of the

computed tomography of the

spine revealing a chalk-stick

fracture through the ankylosed

T9-T10 intervertebral space

opening to the front (arrow)

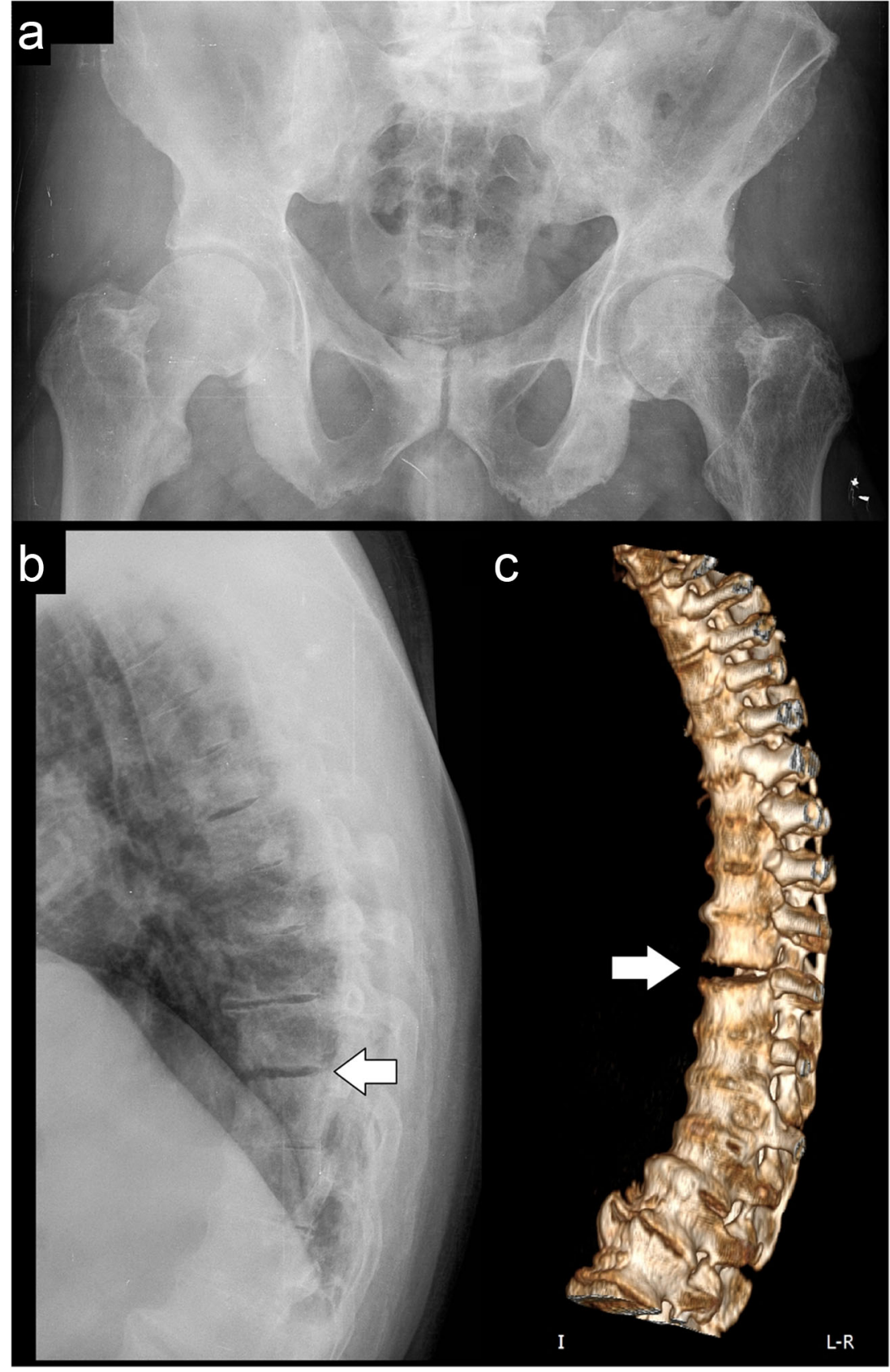

